\title{
Inhibitory Effects of Fluvastatin and Its Metabolites on Hydrogen Peroxide-Induced Oxidative Destruction of Hemin and Low-Density Lipoprotein
}

\author{
Kuniharu Suzumura, ${ }^{*}$ Keiko TanaKa, Mikiko Yasuhara, and Hiroshi Narita \\ Discovery Research Laboratory, Tanabe Seiyaku Co., Ltd., 2-2-50 Kawagishi, Toda, Saitama 335-8505, Japan. \\ Received November 22, 1999; accepted April 10, 2000
}

Some 3-hydroxy-3-methylglutaryl coenzyme A (HMG-CoA) reductase inhibitors, which are used as hypolipidemic drugs, have been reported to have the potential to reduce the oxidizability of plasma low-density lipoprotein (LDL) when they are administered in vivo. Their in vivo mechanism is believed to be closely related to their hypolipidemic action based on the HMG-CoA reductase inhibitory activity. We hypothesized that some type of HMG-CoA reductase inhibitor has additional mechanism inhibiting LDL oxidation in vivo due not to its hypolipidemic action but to its direct antioxidative effect based on its unique chemical structure. We directly compared in vitro the antioxidative effects of well-known HMG-CoA reductase inhibitors (fluvastatin, pravastatin, simvastatin, cerivastatin and atorvastatin) on the hydrogen peroxide-induced oxidative destruction of hemin and LDL. Fluvastatin but not the others showed the inhibitory effect on this system. Its effect was dose-dependent and almost as strong as the natural antioxidants, $\alpha$-tocopherol and ascorbic acid. Further, M2, which is a hydroxylated metabolite of fluvastatin, showed stronger antioxidative activity than did fluvastatin. We suggest that among these HMG-CoA reductase inhibitors, fluvastatin especially has an ability to retard the LDL oxidation which is based on not only its hypolipidemic action but also its direct antioxidative effect.

Key words HMG-CoA reductase inhibitor; lipid peroxidation; antioxidant; fluvastatin; hypolipidemic drug; hemin

Increased level of plasma low-density lipoprotein (LDL) is one of the major risk factors in the progression of atherosclerosis. Hypolipidemic drugs such as 3-hydroxy-3-methylglutaryl coenzyme A (HMG-CoA) reductase inhibitors have been widely used to reduce the risk of atherosclerosis development. ${ }^{1)}$

Oxidative modification of LDL has been thought to be one of the important key steps in the foam cell formation at the early phase of atherosclerosis. ${ }^{2,3)}$ Presence of oxidized lipids has been reported immunohistologically in the arterial vascular walls of human and animals. ${ }^{4,5}$ Further, numerous in vivo studies using antioxidants such as probucol and $\alpha$-tocopherol showed the effectiveness of antioxidant treatment in inhibiting atherosclerosis development in hyperlipidemic subjects. ${ }^{6,7)}$ Although the efficacy of antioxidant therapy in human is not yet clearly established, reducing the oxidizability of LDL and lowering plasma LDL level are believed to be effective ways to reduce the risk of atherosclerosis development. ${ }^{1,8)}$

Some HMG-CoA reductase inhibitors have been reported to decrease the oxidizability of LDL when they are administered in vivo. ${ }^{9-12)}$ Their in vivo antioxidative mechanisms are thought to be closely related to the hypolipidemic action based on the HMG-CoA reductase inhibitory activity, e.g., promotion of the uptake of aged LDL which is more susceptible to oxidation ${ }^{13)}$ from the circulation to the liver, ${ }^{9,10}$ or the modification of the constituents of the lipid in LDL.11,12) However, in spite of the reports of the in vivo antioxidative effects of HMG-CoA reductase inhibitors, there are few which directly compare the chemical antioxidative activities of these inhibitors in vitro.

There are many kinds of HMG-CoA reductase inhibitors used clinically. Lovastatin is a fungal metabolite ${ }^{14)}$; pravas$\operatorname{tatin}^{15)}$ and simvastatin ${ }^{16)}$ were produced by chemical modification of lovastatin; therefore, the structures of these com- pounds closely resemble one another. These compounds have a hydronaphthalene ring which interacts with the coenzyme A recognition site of HMG-CoA reductase, and also have a side chain which mimics mevalonate, whereas other new HMG-CoA reductase inhibitors such as fluvastatin, ${ }^{17)}$ atorvastati $^{18)}$ and cerivastatin ${ }^{19)}$ are totally synthetic compounds with chemical structures distinct from each other and from those of fungal product-derived HMG-CoA reductase inhibitors. Therefore, based on the difference in each chemical structure, each compound may have potential to exhibit some additional effects other than its HMG-CoA reductase inhibitory activity. We hypothesized that some types of HMGCoA reductase inhibitors decrease the oxidizability of LDL in vivo based not only on their hypolipidemic action but also their direct antioxidative effect. In this paper, we attempted to compare the in vitro antioxidative effects of the well-known inhibitors fluvastatin, pravastatin, simvastatin, cerivastatin and atorvastatin on hydrogen peroxide-induced oxidative destruction of hemin and LDL.

Fluvastatin particularly showed the potent effect. Therefore, the antioxidative activities of the major metabolites of fluvastatin in human (Fig. 1) on this system were also investigated to determine the metabolic change in antioxidative activity when administered in vivo.

\section{MATERIALS AND METHODS}

Chemicals Fluvastatin, pravastatin and simvastatin (open acid form) were donated by Tsukuba Research Institute, Novartis Pharma K.K. (Ibaraki, Japan). The metabolites of fluvastatin (M2 and M4, Fig. 1), cerivastatin and atorvastatin were synthesized in the Discovery Research Laboratory, Tanabe Seiyaku Co., Ltd. (Saitama, Japan). Hemin was purchased from Sigma Chemical Co. (Missouri, U.S.A.). Hydrogen peroxide was purchased from Santoku Chemical In- 

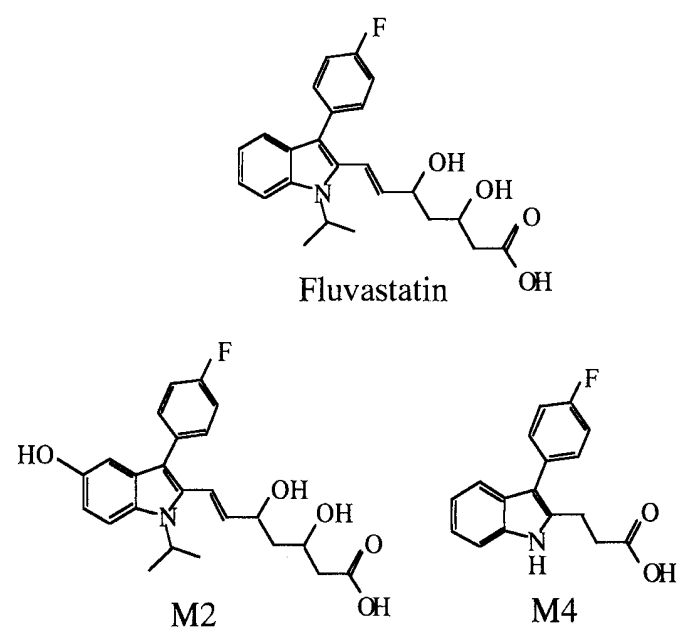

Fig. 1. Chemical Structures of Fluvastatin and Its Major Metabolites in Human

dustries Co., Ltd. (Tokyo, Japan). 2,4,6-tripyridyl-s-triazine (TPTZ) was purchased from Nacalai Tesque Co., Ltd. (Kyoto, Japan). All other reagents used were of the highest grade commercially available.

Preparation of LDL Human LDL in the density range of 1.019 to 1.063 was isolated from fresh EDTA-treated plasma obtained from healthy male volunteers by ultracentrifugation (XL-90 ultracentrifuge, Beckman, California, U.S.A.) at $150000 \mathrm{~g}$ and $4{ }^{\circ} \mathrm{C}$ for $22 \mathrm{~h}^{20)}$ The isolated LDL was stored at $4{ }^{\circ} \mathrm{C}$ until use (for a few days). Just before use, LDL was dialyzed against phosphate buffered saline (PBS, $\mathrm{pH} 7.4$ ) to remove traces of EDTA and then filtered through a $0.22 \mu \mathrm{m}$ filter (Millipore, Massachusetts, U.S.A.). The protein concentration of LDL was measured by BCA protein assay kit (Pierce, Illinois, U.S.A.) with bovine serum albumin as the standard.

Hemin-Hydrogen Peroxide-LDL System Antioxidative effects of the compounds were measured by the hemin-hydrogen peroxide-LDL system which was first reported by Balla et $a l^{21)}$ In this system, it is known that oxidative destruction of hemin and LDL proceeds simultaneously; therefore, measurement of the decrease in absorbance of hemin can be used as a parameter of the oxidation.

In all experiments, $200 \mu \mathrm{g}$ protein $/ \mathrm{ml}$ of LDL in $10 \mathrm{~mm} \mathrm{~N}$ 2-hydroxyethylpiperazine- $N^{\prime}$-2-ethanesulfonic acid (HEPES) with $150 \mathrm{~mm}$ sodium chloride $(\mathrm{pH} 7.4)$ was incubated at $25^{\circ} \mathrm{C}$ in the absence or presence of various concentrations of test compounds from 5 min prior to the start of oxidation for $5 \mathrm{~h}$. Oxidation was initiated by the addition of final concentrations of $10 \mu \mathrm{M}$ hemin and $50 \mu \mathrm{M}$ hydrogen peroxide. Test compounds were dissolved in water or ethanol with the final concentration of ethanol below $1 \%$ which did not show any effect on the oxidation. The process of the oxidation was followed by measuring the decrease in absorbance of hemin at $405 \mathrm{~nm}$ by means of a 96-well microplatereader (Molecular Devices Co., California, U.S.A.). Oxidative destruction of hemin and LDL is terminated when most polyunsaturated fatty acids in LDL are oxidized. The process of the lipid peroxidation is generally divided into three stages: initiation, propagation and termination. ${ }^{22)}$ From the record of the absorbance curve, maximum rate of oxidation in the propagation step and the ending time of oxidation (i.e., the time the propagation step ended) were calculated as parameters of oxidation. The maximum rate of oxidation was calculated by the slope of the line which passed through points of the propagation step. The ending time of oxidation was determined from the intersection of two straight lines: one passing through points of the propagation step and the other passing through the points of the termination step.

In the experiment of Fig. 4, conjugated diene formation in $\mathrm{LDL}^{23)}$ was also followed by measuring the change in absorbance at $234 \mathrm{~nm}$ under the same conditions.

Iron Chelation Study Chelation of $\mathrm{Fe}^{2+}$ or $\mathrm{Fe}^{3+}$ by fluvastatin was examined by the well-known spectrophotometric procedure. ${ }^{24,25)}$ Briefly, $\mathrm{FeSO}_{4}$ or $\mathrm{FeCl}_{3}$ at the concentration of $30 \mu \mathrm{M}$ was injected to HEPES-sodium chloride buffer (pH 7.4) containing $30 \mu \mathrm{M}$ test compound. The spectrum shift of the compound was determined 5 min after addition of iron salt. TPTZ, which is a $\mathrm{Fe}^{2+}$-chelator, was used as a reference compound.

Statistical Analysis Data were expressed as the means \pm S.E.M. of 5 separate experiments. Statistical comparisons among groups were carried out by ANOVA followed by Dunnett's test. For all comparisons, the probability below 5\% was considered to be statistically significant.

\section{RESULTS}

Comparison of the Antioxidative Effects of HMG-CoA Reductase Inhibitors on Hemin-Hydrogen Peroxide-LDL System To compare the in vitro antioxidative activities of HMG-CoA reductase inhibitors, we applied fluvastatin, pravastatin, simvastatin, cerivastatin and atorvastatin to the hemin-hydrogen peroxide-LDL system. Figure 2a shows typical tracings of the experiments. Figures $2 b$ and $2 c$ show the maximum rate and the ending time of oxidation, respectively, which are calculated from each tracing. Among these compounds, fluvastatin $(30 \mu \mathrm{M})$ showed the most marked effect on the system, effectively decreasing the maximum rate of oxidation ( $20 \%$ vs. control) and prolonging the ending time of oxidation $(240 \%$ vs. control). Although simvastatin $(30 \mu \mathrm{M})$ showed a weak effect on this system, the effect was not statistically significant. All other HMG-CoA reductase inhibitors tested $(30 \mu \mathrm{M})$ showed no effect at all.

Antioxidative Effects of Fluvastatin on Hemin-Hydrogen Peroxide-LDL System Figure 3a shows typical tracings, and Figs. $3 b$ and $3 c$ show the maximum rate and the ending time of oxidation, respectively, when fluvastatin was added to this system in a concentration of from 3 to $30 \mu \mathrm{M}$; the inhibitory effect was dose-dependent. The effect was statistically significant at concentrations of more than $10 \mu \mathrm{M}$ at the maximum rate of oxidation and $30 \mu \mathrm{m}$ in the ending time of oxidation, respectively. Fluvastatin's oxidative destruction of hemin and LDL was shown to proceed simultaneously by determining the conjugated diene formation of lipids in LDL under the same conditions. Figure 4 shows typical tracings of the experiments.

Comparison of the Antioxidative Property of Fluvastatin with $\alpha$-Tocopherol and Ascorbic Acid The antioxidative potency of fluvastatin was determined by comparing its potency with well-known natural antioxidants, $\alpha$-tocopherol and ascorbic acid. Figure 5a shows typical tracings of the experiments. Figures $5 \mathrm{~b}$ and $5 \mathrm{c}$ show the maximum rate 


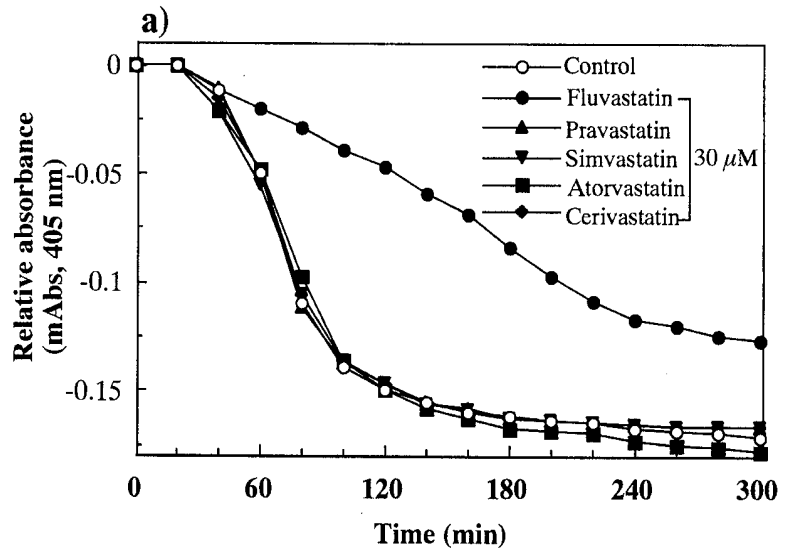

b)
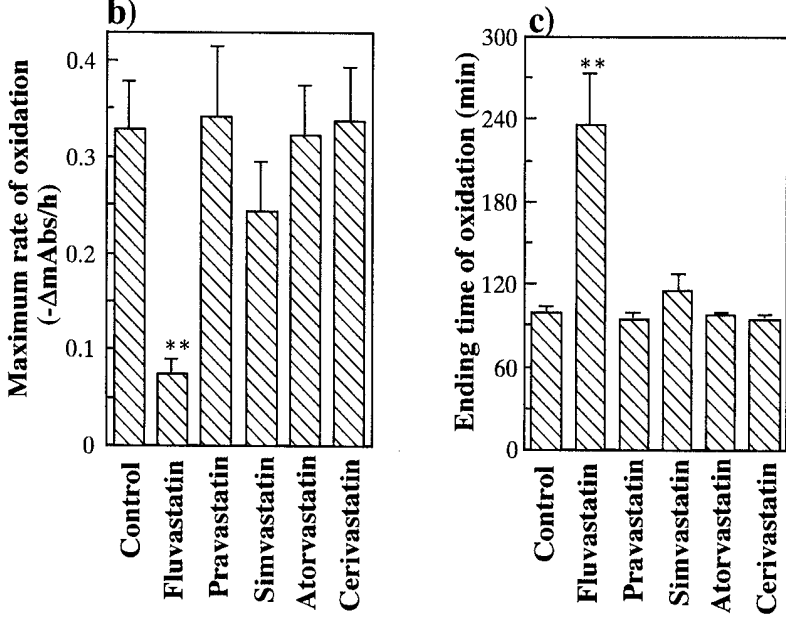

Fig. 2. Comparative Study of the Effects of HMG-CoA Reductase Inhibitors on Hemin-Hydrogen Peroxide-LDL System

a) Typical tracings of the experiments, b) the maximum rate of oxidation and c) the ending time of oxidation. Human LDL $(200 \mu \mathrm{g}$ protein $/ \mathrm{ml})$ in HEPES-sodium chloride buffer $(\mathrm{pH} 7.4)$ was incubated with hemin $(10 \mu \mathrm{M})$ and hydrogen peroxide $(50 \mu \mathrm{M})$ at $25^{\circ} \mathrm{C}$. The absorbance of hemin at the wavelength of $405 \mathrm{~nm}$ was monitored for $5 \mathrm{~h}$. Tested compounds $(30 \mu \mathrm{M})$ were added $5 \mathrm{~min}$ prior to the oxidation. Values are means \pm S.E.M. (Figs. $2 \mathrm{~b}$ and $\mathrm{c}$ ) which were calculated from each tracing $(N=5)$. **: Significantly different from control $(p<0.01)$.

and the ending time of oxidation, respectively, as calculated from each tracing. The pattern of the oxidation in the fluvastatin group was different from those in the reference antioxidant groups. The inhibitor effectively depressed the rate of oxidation and also prolonged the ending time of oxidation, while $\alpha$-tocopherol and ascorbic acid prolonged the ending time of oxidation, but showed no significant effect on the rate of oxidation. The antioxidative potency of fluvastatin was similar to (or even greater than) those of the reference antioxidants judged by the prolongation effect on the ending time of oxidation.

Antioxidative Effects of the Major Metabolites of Fluvastatin The antioxidative mechanism of fluvastatin in vivo was investigated in more detail by evaluating the antioxidative activity of the inhibitor's metabolites as well as fluvastatin itself. Table 1 shows the effects of M2 and M4 (Fig. 1) on the hemin-hydrogen peroxide-LDL system. Although the effect of M4 was weaker than that of fluvastatin, M2 which has a hydroxyl group in its indole moiety showed a marked inhibitory effect on this system, completely suppressing the oxidation at the concentration of $30 \mu \mathrm{m}$. The antioxidative potency of M2 was 3-10 times stronger than that of fluvastatin.

Iron Chelation Study Iron chelation was determined by a)
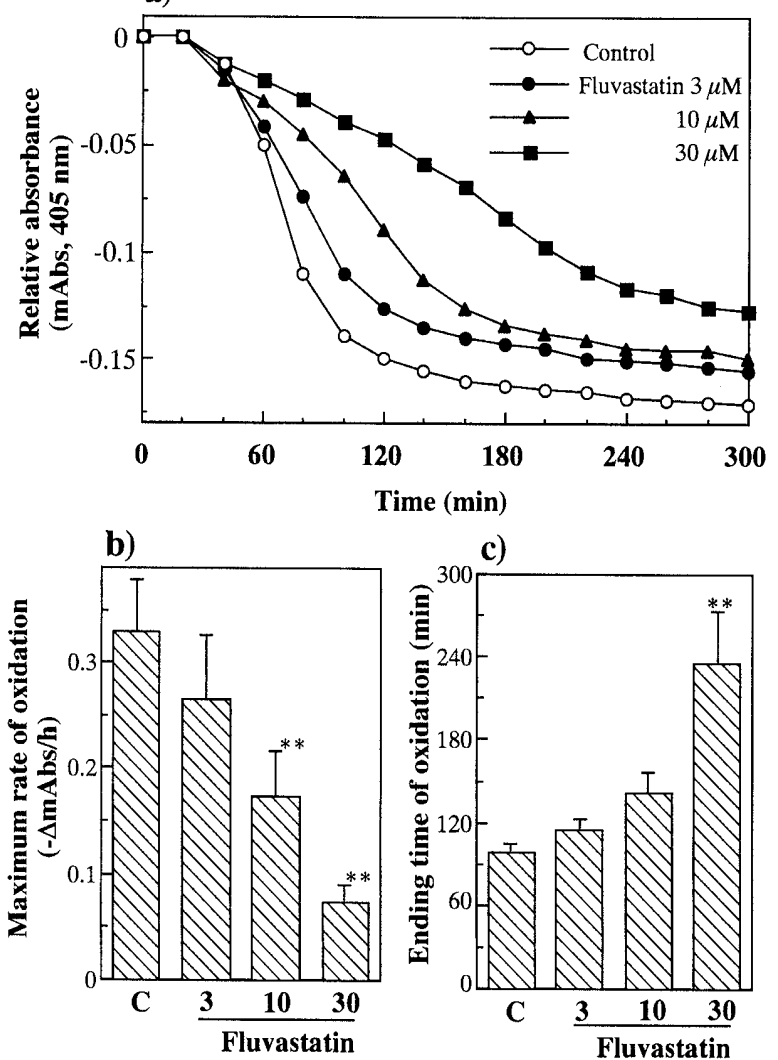

Fig. 3. Effect of Fluvastatin on Oxidative Destruction of Hemin-Hydrogen Peroxide-LDL System

a) Typical tracings of the experiments, b) the maximum rate of oxidation and c) the ending time of oxidation. Human LDL $(200 \mu \mathrm{g}$ protein $/ \mathrm{ml})$ in HEPES-sodium chloride buffer $(\mathrm{pH} 7.4)$ was incubated with hemin $(10 \mu \mathrm{M})$ and hydrogen peroxide $(50 \mu \mathrm{M})$ at $25^{\circ} \mathrm{C}$. The absorbance of hemin at the wavelength of $405 \mathrm{~nm}$ was monitored for $5 \mathrm{~h}$. Fluvastatin $(3,10$ and $30 \mu \mathrm{M})$ was added $5 \mathrm{~min}$ prior to the oxidation. Values are means \pm S.E.M. (Figs. $3 b$ and c) which were calculated from each tracing $(N=5), * *$ : Significantly different from control $(p<0.01)$

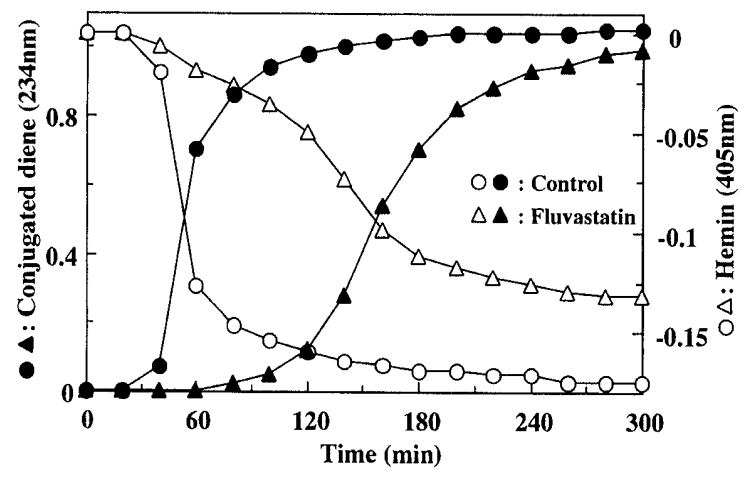

Fig. 4. Typical Tracings of the Conjugated Diene Formation in LDL and Hemin Degradation

Human LDL $(200 \mu \mathrm{g}$ protein/ml) in HEPES-sodium chloride buffer ( $\mathrm{pH} 7.4)$ was incubated with hemin $(10 \mu \mathrm{M})$ and hydrogen peroxide $(50 \mu \mathrm{M})$ at $25^{\circ} \mathrm{C}$ in the presence or absence of fluvastatin $(30 \mu \mathrm{M})$. The destruction of hemin (at the wavelength of $405 \mathrm{~nm}$ ) and the conjugated diene formation (at the wavelength of $234 \mathrm{~nm}$ ) were monitored simultaneously for $5 \mathrm{~h}$.

the spectrophotometric procedure. ${ }^{24,25)}$ TPTZ, which is a $\mathrm{Fe}^{2+}$-chelator, was used as a reference compound. Figure $6 \mathrm{a}$ shows the spectra when $\mathrm{Fe}^{2+}(30 \mu \mathrm{M})$ or $\mathrm{Fe}^{3+}(30 \mu \mathrm{M})$ was added to the fluvastatin solution $(30 \mu \mathrm{m})$. Fluvastatin had two peaks at the wavelengths of 235 and $300 \mathrm{~nm}$. Addition of $\mathrm{Fe}^{2+}$ or $\mathrm{Fe}^{3+}$ did not cause any spectrum shift or absorbance change on the fluvastatin spectrum, while the spectrum of 
TPTZ changed significantly after the addition of $\mathrm{Fe}^{2+}$ as shown in Fig. 6b.

\section{a)}

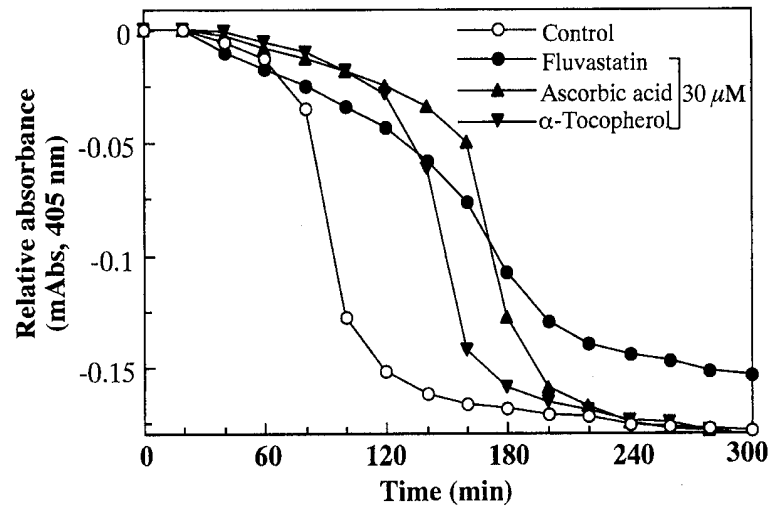

b)
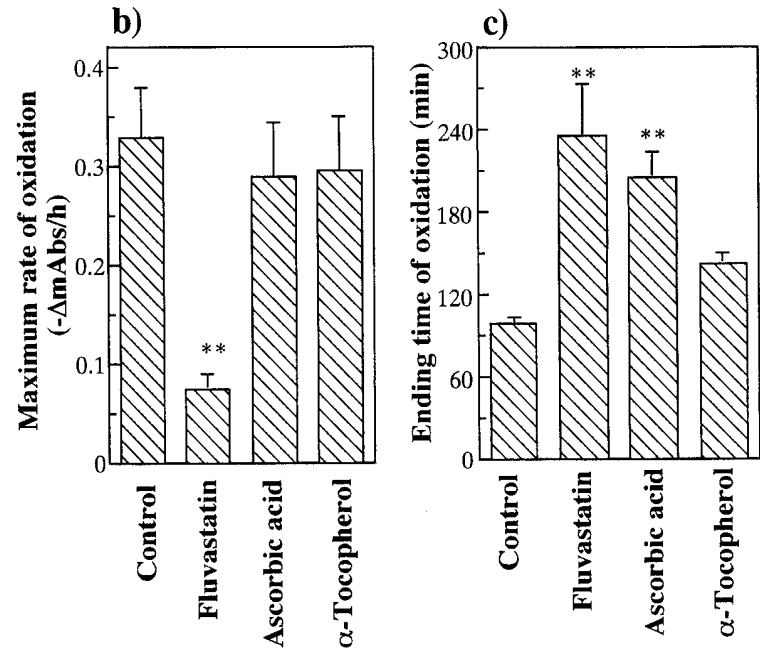

Fig. 5 Comparative Study of the Effects of Fluvastatin with Ascorbic Acid and $\alpha$-Tocopherol on Hemin-Hydrogen Peroxide-LDL System

a) Typical tracings of the experiments, b) the maximum rate of oxidation and c) the ending time of oxidation. Human LDL (200 $\mu \mathrm{g}$ protein/ml) in HEPES-sodium chloride buffer $(\mathrm{pH} 7.4)$ was incubated with hemin $(10 \mu \mathrm{M})$ and hydrogen peroxide $(50 \mu \mathrm{M})$ at $25^{\circ} \mathrm{C}$. The absorbance of hemin at the wavelength of $405 \mathrm{~nm}$ was monitored for $5 \mathrm{~h}$. Tested compounds $(30 \mu \mathrm{M})$ were added $5 \mathrm{~min}$ prior to the oxidation. Values are means \pm S.E.M. (Figs. $5 \mathrm{~b}$ and c) which were calculated from each tracing $(N=5)$. *** Significantly different from control $(p<0.01)$.

\section{DISCUSSION}

In this paper, we directly compared in vitro the antioxidative effects of several HMG-CoA reductase inhibitors on the hemin-hydrogen peroxide-LDL system. Our results clearly indicate that among these inhibitors, fluvastatin particularly has the antioxidative activity and effectively retards the process of LDL oxidation in vitro.

Although the exact mechanisms of the oxidative modification of LDL in vivo remain uncertain, it is believed that the modification of LDL is catalyzed by metal ions, ${ }^{26)}$ lipoxygenase, ${ }^{27)}$ myeloperoxidase, ${ }^{28)}$ peroxynitrite ${ }^{29)}$ and so on. Smith et al. demonstrated that detectable amounts of iron and copper ions exist in human atherosclerotic lesions. ${ }^{26)}$ However, iron and copper are unlikely to exist in free form in normal plasma or interstitial fluids, and the importance of using free copper ion as an inducer of LDL oxidation has been controversial. ${ }^{21)}$ Balla et al. reported that hemin was one of the physiological mediators of LDL oxidation in vivo. ${ }^{21)}$ Hemin is an ubiquitous component of blood and it might be the origin of the iron ion in atherosclerotic lesions. KlipsteinGrobusch et al. reported that high dietary intake of heme iron is related to an increased risk of myocardial infarction. ${ }^{30)}$ Salonen et al. also reported that the reduction of body iron

Table 1. Effects of M2 and M4 on Hemin-Hydrogen Peroxide-LDL System

\begin{tabular}{lccc}
\hline \hline & $\begin{array}{c}\text { Conc. } \\
(\mu \mathrm{M})\end{array}$ & $\begin{array}{c}\text { Maximum rate of oxidation } \\
(-\Delta \mathrm{mAbs} / \mathrm{h})\end{array}$ & $\begin{array}{c}\text { Ending time of oxidation } \\
(\mathrm{min})\end{array}$ \\
\hline Control & 0 & $0.33 \pm 0.05$ & $99 \pm 5$ \\
$\mathrm{M} 2$ & 3 & $0.28 \pm 0.07$ & $138 \pm 11$ \\
& 10 & $0.13 \pm 0.04^{* *}$ & $415 \pm 36^{* *}$ \\
& 30 & $\mathrm{~N}$ & $\mathrm{~N}$ \\
M4 & 30 & $0.26 \pm 0.07$ & $141 \pm 28$ \\
Fluvastatin & 30 & $0.07 \pm 0.02^{* *}$ & $236 \pm 37^{* *}$ \\
\hline
\end{tabular}

Data were calculated using each tracing of the experiments as described in Materials and Methods. Human LDL $(200 \mu \mathrm{g}$ protein/ml) in HEPES-sodium chloride buffer ( $\mathrm{pH}$ 7.4) was incubated with hemin $(10 \mu \mathrm{M})$ and hydrogen peroxide $(50 \mu \mathrm{M})$ at $25^{\circ} \mathrm{C}$. The absorbance of hemin at the wavelength of $405 \mathrm{~nm}$ was monitored for $5 \mathrm{~h}$. Tested compounds $(0-30 \mu \mathrm{M})$ were added $5 \mathrm{~min}$ prior to the oxidation. Values are means \pm S.E.M. $(N=5)$.**: Significantly different from control $(p<0.01)$., N: Not oxidized.
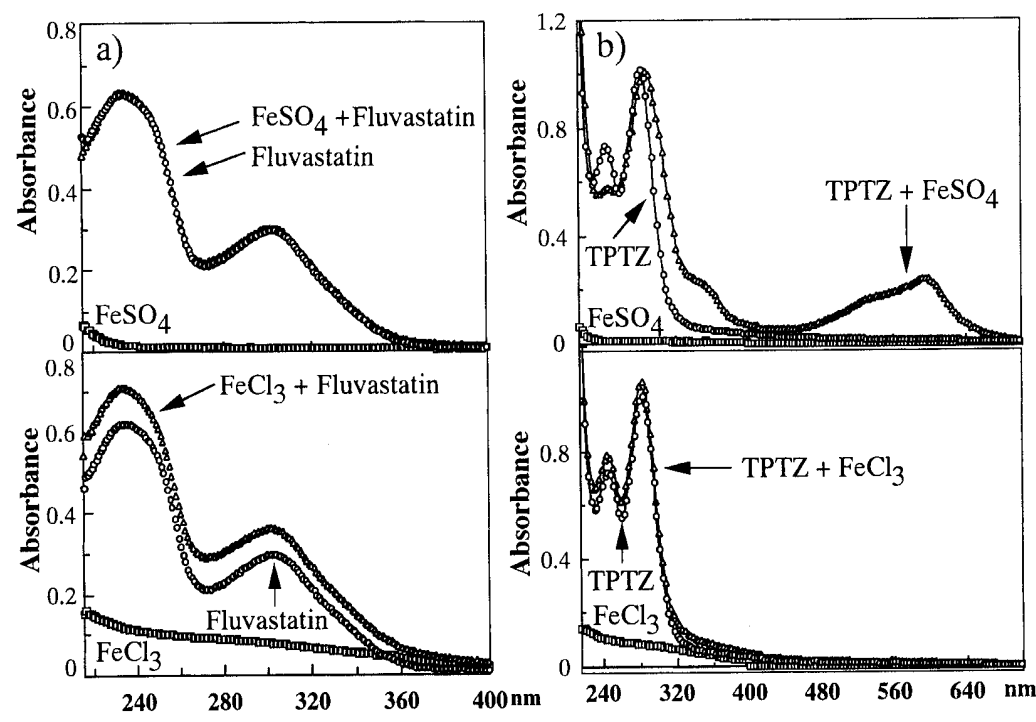

Fig. 6. Iron Chelation Study of Fluvastatin

Spectra of the compound $(30 \mu \mathrm{M})$ in the presence or absence of $\mathrm{FeSO}_{4}$ or $\mathrm{FeCl}_{3}$ at the concentration of $30 \mu \mathrm{M}$ were determined. a) fluvastatin, b) TPTZ. 
stores increased the oxidation resistance of serum lipids. ${ }^{31)}$ Considering these reports, hemin is closely related to the oxidation of lipids in vivo, and the hemin-hydrogen peroxideLDL system seems to be useful as an in vitro model of LDL oxidation.

The mechanism of the hemin-mediated LDL oxidation includes complex reactions, and iron ion and reactive free radicals such as hydroxyl radicals are believed to participate in this oxidation. ${ }^{21)}$ It has been reported that the iron chelator deferoxamine shows strong inhibitory activity on this system. ${ }^{21)}$ However, taking into consideration that fluvastatin did not show a marked iron chelating effect (Fig. 6) but did show a free radical scavenging effect in our recent experiments, ${ }^{32,33)}$ we consider that its inhibitory effect on this system was due primarily to its radical scavenging property rather than its iron chelating effect.

The chemical structures of HMG-CoA reductase inhibitors generally have a mevalonate mimic side chain which is important for the inhibition of HMG-CoA reductase. However, their other partial structures differ from one another, especially in those of the totally synthetic new HMG-CoA reductase inhibitors (fluvastatin, atorvastatin and cerivastatin). Therefore, each compound may have potential to show an unexpected feature such as the antioxidative activity of fluvastatin as described in this paper. Fluvastatin has an indole ring which is believed to be important for manifestation of this activity ${ }^{34,35)}$; further, the double bond, which is conjugated with the fluorophenyl substituted indole ring (Fig. 1), is also thought to be closely related to the activity. ${ }^{36,37)}$

The relative antioxidative potency of fluvastatin was estimated by comparison with those of $\alpha$-tocopherol and ascorbic acid; its inhibitory potency on the oxidation was quite similar to that of $\alpha$-tocopherol, although the pattern of the oxidation was different (Fig. 5). Fluvastatin depressed the maximum rate of oxidation and prolonged the ending time of oxidation, while $\alpha$-tocopherol did not show a significant effect on the maximum rate of oxidation in the propagation step, although it effectively prolonged the initiation step and ending time of oxidation. $\alpha$-Tocopherol is known as a phenolic antioxidant and its antioxidative mechanism is based on the release of a hydrogen atom to the lipid peroxidized radical. ${ }^{38)}$ In the process of LDL oxidation, phenolic antioxidants are consumed along with other antioxidants immediately after the start of oxidation, and when most of them are oxidized, the propagation step begins. ${ }^{22)}$ Therefore, it is reasonable that $\alpha$-tocopherol effectively extended the initiation step and the ending time of oxidation, but did not reduce the maximum rate of oxidation in the propagation step. The precise mechanism of the difference between the effects of fluvastatin and $\alpha$-tocopherol is uncertain. However, injected fluvastatin is thought to have remained even after phenolic antioxidants were exhausted, which reduced the rate of oxidation in the propagation step.

According to a pharmacokinetic study, the component of fluvastatin which has the highest concentration in plasma after its oral administration, is unchanged fluvastatin. ${ }^{39,40)}$ The mean highest plasma concentration of fluvastatin after multiple oral administrations at a dose of $40 \mathrm{mg} \mathrm{gd}$ $(0.56 \mathrm{mg} / \mathrm{kg})$ for a period of 6 days was almost $1 \mu \mathrm{M} .{ }^{39)}$ The effective concentration of fluvastatin in this paper seems somewhat higher than the concentration in human plasma when it is clinically administered in vivo; however, under these experimental conditions, the oxidative destruction of hemin and LDL was nearly completed within 2 or $3 \mathrm{~h}$. Taking into account that the oxidative modification of LDL in vivo progresses more slowly under milder physiological conditions, ${ }^{13)}$ we suggest that fluvastatin has a chance to show the antioxidative effect in vivo. The potential of its antioxidative ability is further supported by the results that fluvastatin showed similar (or even greater) antioxidative activity compared with those of the reference natural antioxidants.

M2 and M4 (Fig. 1) are the major metabolites of fluvastatin in human after oral administration. ${ }^{40)} \mathrm{M} 4$ is the most abundant compound in plasma except for unchanged fluvastatin. Although M2 exists at a low level in plasma, a large quantity is excreted in the feces and it is believed to exist mainly in liver.

Because M2 has a stronger activity than fluvastatin, metabolic hydroxylation seems to be important for the potentiation of this activity. This belief is further supported by the data that another metabolite, M3 which has a phenolic hydroxyl group at 6-position of the indole moiety of fluvastatin, showed a similarly potent antioxidative effect (data not shown). Our results suggest that the metabolites of fluvastatin also have potential to contribute to the antioxidative effect of this inhibitor in vivo. Although we did not examine the antioxidative activities of the metabolites of other statins, there is a possibility that some hydroxylated metabolites of another HMG-CoA reductase inhibitors also show the antioxidative effects to some extent, as reported by Aviram et al. ${ }^{41)}$

It has been reported that HMG-CoA reductase inhibitors have abilities to retard the LDL oxidation in vivo, and the antioxidative mechanisms have been thought to be mainly associated with the hypolipidemic action such as promotion of the removal of aged LDL from the circulation ${ }^{9,10)}$ or modification of the constituents of the lipids in LDL. ${ }^{11,12)}$ From the results in this paper, we suggest that among these HMG-CoA reductase inhibitors, fluvastatin especially has an ability to retard LDL oxidation, which is based on not only its hypolipidemic action but also its direct antioxidative effect.

Accumulated evidence supports the hypothesis that oxidative modification of LDL plays an important role in atherogenesis. ${ }^{2,3)}$ Oxidized LDL is recognized and taken up by macrophages via the scavenger receptor pathway. The scavenger receptor is not regulated by intracellular cholesterol concentration, and the unregulated LDL uptake leads to foam cell formation in the early phase of atherosclerosis. ${ }^{2,3)} \mathrm{A}$ number of studies have indicated that synthetic antioxidants protected LDL from oxidative modification in vivo and reduced the development of atherosclerosis. ${ }^{6,7)}$ Therefore, the antioxidative property of fluvastatin would be beneficial as a hypolipidemic drug in reducing the progression of this condition.

There are many clinical trials which investigate the benefit of lipid-lowering therapy against coronary heart disease (CHD). Among them, The Lipoprotein and Coronary Atherosclerosis Study (LCAS) ${ }^{42)}$ was conducted to determine whether lipid-lowering therapy with fluvastatin would reduce the progression of coronary atherosclerotic lesions and/or new coronary lesion formation in patients with CHD and moderately elevated LDL cholesterol. In this study, fluvas- 
tatin-treatment significantly slowed the CHD progression after 2.5 years. Interestingly, the angiographic benefit observed in LCAS was as great as that in trials which achieved a greater reduction in LDL cholesterol by other HMG-CoA reductase inhibitors. ${ }^{42}$ This additional benefit may be, at least in part, derived from the antioxidative property of fluvastatin in vivo. In fact, several investigators have reported the antioxidative effect of fluvastatin in vivo. ${ }^{9,10,43-45)} \mathrm{We}$ speculate that fluvastatin serves as a good prophylactic agent for atherosclerosis by depressing both the plasma level and oxidation of LDL.

Acknowledgment We would like to thank Dr. T. Suzuki for his helpful discussion throughout the study.

\section{REFERENCES}

1) Steinberg D., Atherosclerosis, 131, S5-S7 (1997).

2) Steinberg D., Parthasarathy S., Carew T. E., Khoo J. C., Witztum J. L., N. Engl. J. Med., 320, 915-924 (1989).

3) Witztum J. L., Steinberg D., J. Clin. Invest., 88, 1785-1792 (1991).

4) Boyd H. C., Gown A. M., Wolfbauer G., Chait A., Am. J. Pathol., 135, 815-825 (1989).

5) Ylä-Herttuala S., Palinski W., Rosenfeld M. E., Parthasarathy S., Carew T. E., Butler S., Witztum J. L., Steinberg D., J. Clin. Invest., 84, 1086-1095 (1989).

6) Carew T. E., Schwenke D. C., Steinberg D., Proc. Natl. Acad. Sci. U.S.A., 84, 7725-7729 (1987).

7) Daugherty A., Roselaar S. E., Cardiovasc. Res., 29, 297-311 (1995).

8) Rice-Evans C. A., Diplock A. T., Free. Rad. Biol. Med., 15, 77-96 (1993).

9) Aviram M., Eur. J. Clin. Chem. Clin. Biochem., 34, 599-608 (1996).

10) Aviram M., Hussein O., Rosenblat M., Schlezinger S., Hayek T., Keidar S., J. Cardiovasc. Pharmacol., 31, 39-45 (1998).

11) Kleinveld H. A., Demacker P. N. M., De Haan A. F. J., Stalenhoef A. F. H., Eur. J. Clin. Invest., 23, 289-295 (1993).

12) Salonen R., Nyyssönen K., Porkkala-Sarataho E., Salonen J. T., Am. J. Cardiol., 76, 34C-39C (1995).

13) Walzem R. L., Watkins S., Frankel E. N., Hansen R. J., German J. B., Proc. Natl. Acad. Sci. U.S.A., 92, 7460-7464 (1995).

14) Henwood J. M., Heel R. C., Drugs, 36, 429-454 (1988).

15) McTavish D., Sorkin E. M., Drugs, 42, 65-89 (1991).

16) Todd P. A., Goa K. L., Drugs, 40, 583-607 (1990).

17) Plosker G. L., Wagstaff A. J., Drugs, 51, 433-459 (1996).

18) Lea A. P., McTavish D., Drugs, 53, 828-847 (1997).

19) McClellan K. J., Wiseman L. R., McTavish D., Drugs, 55, 415-422 (1998).

20) Havel R. J., Eder H. A., Bragdon J. H., J. Clin. Invest., 34, 1345-1353 (1955).

21) Balla G., Jacob H. S., Eaton J. W., Belcher J. D., Vercellotti G. M., Arterioscler. Thromb., 11, 1700-1711 (1991).
22) Esterbauer H., Puhl H., Dieber-Rotheneder M., Waeg G., Rabl H., Annal. Med., 23, 573-581 (1991).

23) Puhl H., Waeg G., Esterbauer H., Methods Enzymol., 233, 425-441 (1994).

24) Braughler J. M., Burton P. S., Chase R. L., Pregenzer J. F., Jacobsen E. J, VanDoornik F. J., Tustin J. M., Ayer D. E., Bundy G. L., Biochem. Pharmacol., 37, 3853-3860 (1988).

25) Ko F. N., Liao C. H., Kuo Y. H., Lin Y. L., Biochim. Biophys. Acta, 1258, 145-152 (1995).

26) Smith C., Mitchinson M. J., Aruoma O. I., Halliwell B., Biochem. J., 286, 901-905 (1992).

27) YLÄ-Herttuala S., Rosenfeld M. E., Parthasarathy S., Glass C. K., Sigal E., Witztum J. L., Steinberg D., Proc. Natl. Acad. Sci. U.S.A., 87, 6959-6963 (1990).

28) Daugherty A., Dunn J. L., Rateri D. L., Heinecke J. W., J. Clin. Invest., 94, 437-444 (1994).

29) Graham A., Hogg N., Kalyanaraman B., O’Leary V., Darley-Usmar V., Moncada S., FEBS Lett., 330, 181-185 (1993).

30) Klipstein-Grobusch K., Grobbee D. E., Den Breeijien J. H., Boeing H., Hofman A., Witteman J. C. M., Am. J. Epidemiol., 149, 421-428 (1999).

31) Salonen J. T., Korpela H., Nyyssönen K., Porkkala E., Tuomainen T.P., Belcher J. D., Jacobs D. R., Jr., Salonen R., J. Intern. Med., 237, $161-168(1995)$.

32) Suzumura K., Yasuhara M., Tanaka K., Odawara A., Narita H., Suzuki T., Chem. Pharm. Bull., 47, 1010-1012 (1999).

33) Suzumura K., Yasuhara M., Narita H., Chem. Pharm. Bull., 47, $1477-1480$ (1999).

34) Kagan V. E., Tsuchiya M., Serbinova E., Packer L., Sies H., Biochem. Pharmacol., 45, 393-400 (1993).

35) Steenken S., Sundquist A. R., Jovanovic S. V., Crockett R., Sies H., Chem. Res. Toxicol., 5, 355-360 (1992).

36) Suzumura K., Yasuhara M., Tanaka K., Suzuki T., Biochem. Pharmacol., 57, 697-703 (1999).

37) Nakamura T., Nishi H., Kokusenya Y., Hirota K., Miura Y., Chem. Pharm. Bull., 48, 235-237 (2000).

38) Niki E., Saito T., Kawakami A., Kamiya Y., J. Biol. Chem., 259, 4177-4182 (1984).

39) Tse F. L. S., Jaffe J. M., Troendle A., J. Clin. Pharmacol., 32, 630638 (1992).

40) Dain J. G., Fu E., Gorski J., Nicoleti J., Scallen T. J., Drug. Metab. Dispos., 21, 567-572 (1993).

41) Aviram M., Rosenblat M., Bisgaier C. L., Newton R. S., Atherosclerosis, 138, 271-280 (1998).

42) Herd J. A., Ballantyne C. M., Farmer J. A., Ferguson J. J., III, Jones P. H., West M. S., Gould K. L., Gotto A. M., Jr., Am. J. Cardiol., 80, 278-286, (1997).

43) Mitani H., Bandoh T., Ishikawa J., Kimura M., Totsuka T., Hayashi S., Brit. J. Pharmacol., 119, 1269--1275 (1996).

44) Hussein O., Schlezinger S., Rosenblat M., Keider S., Aviram M., Atherosclerosis, 128, 11-18 (1997).

45) Leonhardt W., Kurktschiev T., Meissner D., Lattke P., Abletshauser C., Weidinger G., Jacross W., Hanefeld M., Eur. J. Clin. Pharmacol., 53, $65-69$ (1997). 